\title{
The relationship between weight change and C3 complement levels in patients with anorexia nervosa
}

\author{
Atila Erol $^{1}$, Mustafa Ozten $^{1}$ \\ 'Sakarya University, Faculty of Medicine, Department of Psychiatry, Sakarya - Turkey
}

\begin{abstract}
Objective: Anorexia Nervosa (AN) affects the entire body with serious medical conditions and has the highest mortality rates in any psychiatric disorder. These medical abnormalities are reversible after weight gain and resolution of the underlying anorectic state. The role of the immune system in the development and maintenance of AN is apparently underestimated. Changes in the complement system, particularly $\mathrm{C} 3$ in AN, are not well understood. This study was designed to evaluate changes in body weight and complement C3 levels.

Method: This study was designed as a prospective study on 12 female AN patients. Serum samples were taken biweekly for 4 times. The serum levels of complement C3 levels were quantified and correlated with the body mass index (BMI). Repeated measures of ANOVA were used to determine changes in BMI and C3 complement levels. A generalized estimating equation (GEE) analysis was used to determine the relationship between BMI and complement C3 levels over time.

Results: An increase in C3 levels was observed in the analysis of the data according to the increase in body weight of the patients as a result of eating of AN patients. There was a significant increase in C 3 levels $(p=0.042)$ and BMI levels of the patients $(p=0.01)$. The increase in BMI was followed by the increase in C3 level. BMI increases over time were statistically correlated with changes in C3 levels.

Conclusion: Increasing C3 levels with increasing BMI during the treatment process are parallel. Complement 'C3' serum levels potentially serving as a guide for monitoring the refeeding process also could be a useful marker for determining and monitoring the treatment success in AN.
\end{abstract}

Keywords: Anorexia nervosa, body mass index, complement levels, weight change

\section{INTRODUCTION}

Anorexia Nervosa (AN) appears to affect the whole body with serious medical conditions and has the highest mortality rate in any psychiatric disorder $(1,2)$. The degree of metabolic and physiological changes that occur depends on the duration and severity of intake reduction and the amount of weight loss (3). The treatment process is long and difficult due to serious medical conditions (1). However these medical abnormalities can be reversed after weight gain and reso-lution of the underlying anorectic condition. To date, there is no definitive marker that monitors the treatment process or progression of the disease $(4,5)$.

The pathogenesis of an increasing number of chronic diseases has been attributed to effects of the immune system, the role of immune system in the development and maintenance of anorexia nervosa is apparently not

How to cite this article: Erol A, Ozten M. The relationship between weight change and C3 complement levels in patients with anorexia nervosa. Dusunen Adam The Journal of Psychiatry and Neurological Sciences 2021;34:97-101.

Correspondence: Mustafa Ozten, Sakarya University, Faculty of Medicine, Department of Psychiatry, Sakarya - Turkey 
sufficiently appreciated, but while immunological changes are diffi-cult to explain due to secondary malnutrition alone, the exact pathogenesis of these immunolog-ical changes in anorexia nervosa is unclear, the immune system may actually be causative in the pathogenesis and maintenance of anorexia nervosa (6). Traditional cascade pathways and repre-sents the first-line defense mechanism against pathogens (7-10). Most of the complement proteins are synthesized by the liver and macrophages $(7,9,10)$. Recent studies show that adipose tissue is the production site of some complement proteins, suggesting links between the energy balance system and the immunity (11-15). Studies on complement levels with low body weight show that malnutrition has been associated with multiple immunologic deficits and decreased complement levels, particularly 'C3' and factor B (16-22). Although it is unclear that low com-plement levels are caused by impaired production or chronic activation of the complement cas-cade by recurrent infections $(21,23)$. Moreover, AN has traditionally been viewed as a malnourishment disease, patients do not usually have superimposed inflammatory states, such as infection or malignancy, which raise the levels of certain complement proteins $(24,25)$. Reports of complement components of a few AN patients, especially alternative pathways may be insuf-ficient, but this has not been systematically studied (26-28).

We hypothesized that weight loss in AN results in C3 consumption, and serum C3 levels would increase with weight gain over the course of treatment, and therefore C3 levels may be a useful marker for monitoring the treatment success in AN.

Even the most anorexic patients may present with normal laboratory values, underscoring the need for a new sensitive biomarker. This study was designed to evaluate complement levels in patients with anorexia nervosa, and to determine whether complement serum levels may repre-sent a useful marker for determining and monitoring the disease. Therefore, this study was de-signed to evaluate changes of complement C3 levels with body weight changes in AN.

\section{METHOD}

\section{Patients}

Twelve AN patients were recruited from the outpatient psychiatry clinic of Sakarya University Faculty of Medicine.

The inclusion criteria were as follows:

(i) 18 years of age or older;

(ii) AN diagnosis.
The exclusion criteria were as follows:

(i) the presence of acute (e.g., infections, diseases) or chronic disease affecting complement levels (e.g., hypertension, diabetes, liver disease, kidney diseases, current thyroid dysfunction, or neurological disease);

(ii) existing comorbid Axis I disorders.

The ethics committee of Sakarya University Faculty of Medicine was obtained. All procedures were performed after participants had demonstrated adequate understanding and provided written informed consent. The patients received diet and appetiteenhancing medication.

\section{Blood Sampling}

Blood samples were obtained every 2 weeks in the morning during the fasting period. Bodyweight and C3 levels were assessed every two weeks. Patients were under acute phase treatment (weight gain period) followed up for 6 weeks, so each patient has 4 (beginning, second, fourth, and sixth week) laboratory and weight results.

\section{Statistical Analysis}

Key characteristics of the study participants are defined by mean and standard deviation (SD) or percentages. Repeated measures of ANOVA were used to determine changes in body mass index (BMI) and C3 complement levels. The Generalized Estimating Equations procedure extends the generalized linear model to allow analysis of repeated measurements to determine the relationship between BMI and complement C3 level over time for the anorexia nervosa patients. Differences were considered significant when $\mathrm{p}<0.05$.

\section{RESULTS}

All patients were women with a mean age of 23.4 $(\mathrm{SD}=6.5)$, and a mean height of $159 \mathrm{~cm}(\mathrm{SD}=4.3)$. The initial mean body mass of BMI of patients: 14.96 $(\mathrm{SD}=1.70)$ and $\mathrm{C} 3$ levels $0.88 \mathrm{~g} / \mathrm{lt}(\mathrm{SD}=0.19)$, at the second week of treatment average BMI: 16.01 $(\mathrm{SD}=1.76)$ and $\mathrm{C} 3$ levels $0,96 \mathrm{~g} / \mathrm{lt}(\mathrm{SD}=0.21)$, at the fourth week of treatment average BMI: 16.86 $(\mathrm{SD}=2.06)$ and $\mathrm{C} 3$ levels $1.03 \mathrm{~g} / \mathrm{lt}(\mathrm{SD}=0.33)$, at the end of treatment (sixth week) average BMI: 17.38 $(\mathrm{SD}=1.77)$ and $\mathrm{C} 3$ levels $1.16 \mathrm{~g} / \mathrm{lt}(\mathrm{SD}=0.31)$ of the twelve patients. Repeated measures of ANOVA were used to determine changes in BMI and C3 complement levels over time. There was a significant increase in $\mathrm{C} 3$ levels $(\mathrm{p}=0.042)$ and BMI levels of patients $(\mathrm{p}=0.01)$. The increase in BMI was followed by an increase in C3 
Table 1: BMI and C3 levels over time

\begin{tabular}{lcccc} 
& \multicolumn{2}{c}{$\mathbf{B M I}\left(\mathbf{k g} / \mathbf{m}^{2}\right)$} & \multicolumn{2}{c}{$\mathbf{C 3}(\mathbf{g} / \mathbf{l t})$} \\
\cline { 2 - 5 } & Mean & SD & Mean & SD \\
\hline $\mathbf{0}^{\text {th }}$ week & 14.96 & 1.70 & 0.88 & 0.19 \\
$\mathbf{2}^{\text {th }}$ week & 16.01 & 1.76 & 0.96 & 0.21 \\
$\mathbf{4}^{\text {th }}$ week & 16.86 & 2.06 & 1.03 & 0.33 \\
$\mathbf{6}^{\text {th }}$ week & 17.38 & 1.77 & 1.16 & 0.31 \\
\hline
\end{tabular}

BMI: Body mass index, SD: Standard deviation

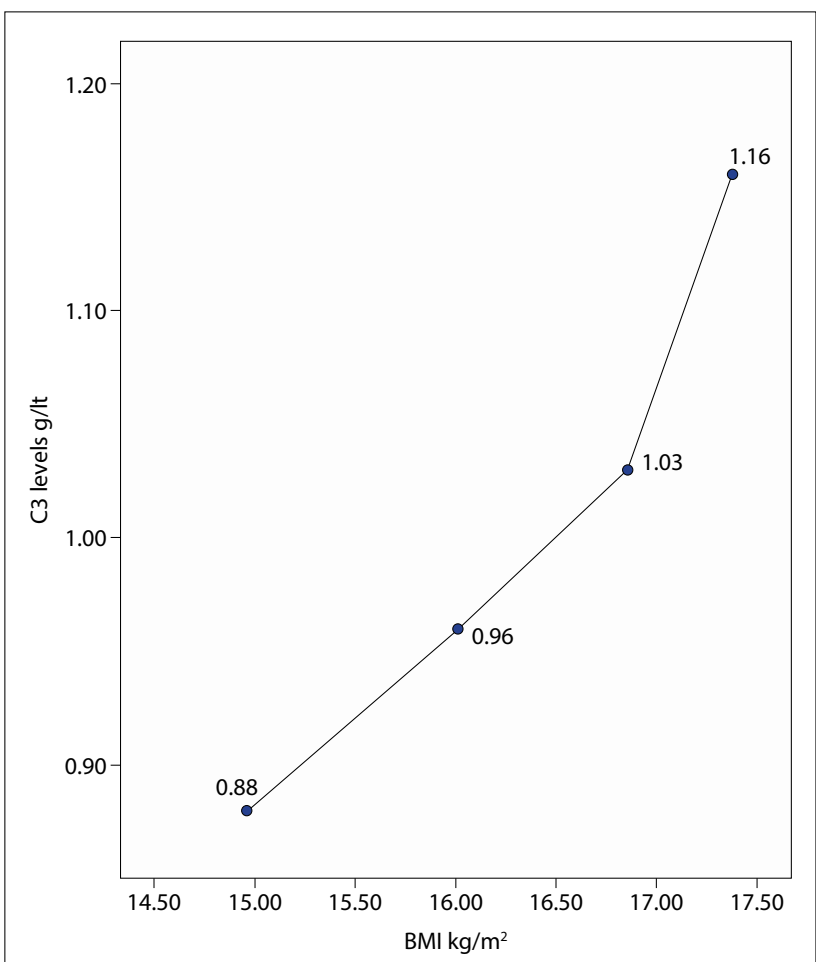

Figure 1. Correlation between BMI and complement C3 levels over time.

level (Table 1). The Generalized Estimating Equations was used to determine the correlation between BMI and complement C3 levels over time. There was a statistically significant correlation between $\mathrm{C} 3$ and BMI changes. $(\% 95 \mathrm{CI}, 1.010$ to 1.014 and $\mathrm{p}=0.02)$ (Fig. 1).

\section{DISCUSSION}

Levels of complement components varied with changes in body weight. As in other forms of starvation, complement levels were significantly decreased in lowweight anorectics even in the absence of complement activation by opportunistic infections and in protein deficiency which caused decreased serum complement levels (21). Our study provides that the decrease in complement $\mathrm{C} 3$ serum levels in AN patients increased with weight gain. These results support that body weight changes play a significant role in determining serum complement C3 levels.

Flierl et al. reported that complement consumption was secondary to increased activation in anorexic patients (29). Some authors have also suggested that the synthesis of $\mathrm{C} 3$ and transfer-rin in $\mathrm{AN}$ patients might be affected as a result of changes in the adipose tissue deposit (30). Adipose cells also synthesize other essential components of the alternative pathway, especially C3 and B (31). Pomeroy et al. (30) reported low serum complement levels due to hypoproduc-tion in $\mathrm{AN}$. We concluded that both activation of the complement cascade by consumption and, alternatively, hypoproduction can be attributed to lower serum C3 levels in AN. However, there were no other consequences in the chronic activation of any disease or complement, such as any infection or malignancy, in patients throughout the study. Therefore, we thought that hypoproduction is the major cause of decreased complement $\mathrm{C} 3$ levels in AN in these patients.

There are few reports on complement levels in anorexia nervosa patients. Wyatt et. all published a series of five anorexia nervosa patients and observed significantly decreased serum levels of C1q, C2, C3, factor $\mathrm{B}, \mathrm{b}$ luteinizing hormone (b-LH), C3b inactivator, properdin, and $\mathrm{C} 4$ bind-ing protein. After the initiation of alimentation, b-LH, C3b inactivator, $\mathrm{C} 3$, and factor $\mathrm{B}$ rapidly returned to the normal range in response to therapy (28). In line with these findings, Sigal et al. found low serum complement proteins levels in anorexia nervosa patients (32). A more recent report evaluated several components of the complement cascade and analyzed the activities of the alternative complement activation pathways (30). Serum levels of C3, Factor B and D, the hemolytic activity of the alternative pathway, and the inhibitors $\mathrm{H}$ and I were found to be low in anorexia patients and returned to normalwith weight gain (30). And recent studies have exam-ined complement hemolytic activation and complement hemolytic activity in anorexia nervosa patients and reported significantly lower serum C3 levels in AN compared to healthy controls, and a strong correlation between index C3 levels and BMI (29). In our study, we determined significantly decreased C3 complement levels in patients with anorexia nervosa, which is in line with previous findings. However, our study shows that C3 levels increase with weight restora-tion. Therefore, there may be complement $\mathrm{C} 3$ serum levels potentially 
serving as a guide for monitoring the refeeding process.

As a result of general malnutrition, many laboratory anomalies are detected, while low $\mathrm{C} 3$ can be considered as a sign of low body weight. It is reasonable that serum C3 levels correlated with body weight in the anorexia group, reflecting the fact that a 'threshold' of severe illness caused by anorexia has been exceeded at these profoundly low body weights.

Low body weight and changes in body weight affect serum complement C3 levels. Low com-plement C3 levels were associated with increased risk of infection or other clinical pathologies with activation and consumption of complement cascade or were due to hypoproduction in adi-pose tissue or other sites of the body.

In our patients, not only low body weight, but also clinical features such as body image distor-tion and an intense fear of gaining weight decreased with increased C3 levels. Hence, C3 levels may represent treatment success to monitor.

Our study has a few limitations. Low patient numbers limit the power of our statistical analysis and make our data vulnerable to a statistical type II error. Therefore, our data do not allow ad-vocating complement serum levels as a marker for determining and monitoring the treatment until it is definitively proven in future large-scale prospective studies. And one of the limitations of our study is the absence of healthy control group.

In conclusion, our findings clearly demonstrate the role of body weight in determining levels of complement C3. C3 levels statistically correlated with weight restoration during treatment and thus $\mathrm{C} 3$ levels may be a useful marker for determining and monitoring treatment success in AN.

\begin{tabular}{|c|c|c|}
\hline \multicolumn{2}{|c|}{ Contribution Categories } & Author Initials \\
\hline \multirow{3}{*}{ Category 1} & Concept/Design & A.E. \\
\hline & Data acquisition & A.E., M.O. \\
\hline & Data analysis/Interpretation & A.E., M.O. \\
\hline \multirow{2}{*}{ Category 2} & Drafting manuscript & A.E., M.O. \\
\hline & Critical revision of manuscript & A.E., M.O. \\
\hline Category 3 & Final approval and accountability & A.E., M.O. \\
\hline \multirow{2}{*}{ Other } & Technical or material support & A.E., M.O. \\
\hline & Supervision & A.E. \\
\hline
\end{tabular}

Ethics Committee Approval: Study was approved by the Ethics Committee of Sakarya University Faculty of Medicine.

Informed Consent: During research the patient's oral and written informed consent was obtained from.
Peer-review: Externally peer-reviewed

Conflict of Interest: We declare that we have no conflicts of interest.

Financial Disclosure: We declare that we have no any financial support.

\section{REFERENCES}

1. Mehler PS, Krantz M. Anorexia nervosa medical issues. J Womens Health (Larchmt) 2003; 12:331-340.

2. Casper RC. The pathophysiology of anorexia nervosa and bulimia nervosa. An-nu Rev Nutr 1986; 6:299-316.

3. Mehler PS, Winkelman AB, Andersen DM, Gaudiani JL. Nutritional rehabilitation: practical guidelines for refeeding the anorectic patient. J Nutr Metab 2010; 2010:625782.

4. Steinhausen HC. The outcome of anorexia nervosa in the 20th century. Am J Psychiatry 2002; 159:1284-1293.

5. Prince AC, Brooks SJ, Stahl D, Treasure J. Systematic review and meta-analysis of the baseline concentrations and physiologic responses of gut hormones to food in eating disorders. Am J Clin Nutr 2009; 89:755-765.

6. Gibson D, Mehler PS. Anorexia nervosa and the immune system-a narrative re-view. J Clin Med 2019; 8:1915.

7. Colten HR, Rosen FS. Complement deficiencies. Annu Rev Immunol 1992; 10:809-834.

8. Huber-Lang M, Sarma JV, Zetoune FS, Rittirsch D, Neff TA, McGuire SR, et al. Generation of C5a in the absence of C3: a new complement activation pathway. Nat Med 2006; 12:682-687.

9. Dalmasso AP. Complement in the pathophysiology and diagnosis of human di-seases. Crit Rev Clin Lab Sci 1986; 24:123-183.

10. Frank MM. The complement system: In Samter M, Talmage DW, Frank MM, Austen KR, Claman HN (editors). Immunological diseases. Boston: Little, Brown and Co. Inc. 1988, 203-232.

11. Flier JS, Lowell B, Napolitano A, Usher P, Rosen B, Cook KS, et al. Adipsin: regulation and dysregulation in obesity and other metabolic states. Recent Prog Horm Res 1989; 45:567-580.

12. Lowell BB, Flier JS. Differentiation dependent biphasic regulation of adipsin gene expression by insulin and insulin-like growth factor-1 in 3T3-F442A adipocy-tes. Endocrinology 1990; 127:2898-2906.

13. Rosen BS, Cook KS, Yaglom J, Groves DL, Volanakis JE, Damm $\mathrm{D}$, et al. Adip-sin and complement factor D activity: an immunerelated defect in obesity. Science 1989; 244:1483-1487.

14. Spiegelman BM, Lowell B, Napolitano A, Dubuc P, Barton $\mathrm{D}$, Francke U, et al. Adrenal glucocorticoids regulate adipsin gene expression in genetically obese mi-ce. J Biol Chem 1989; 264:1811-1815.

15. White RT, Damm D, Hancock N, Rosen BS, Lowell BB, Usher $\mathrm{P}$, et al. Human adipsin is identical to complement factor D and is expressed at high levels in adipo-se tissue. J Biol Chem 1992; 267:9210-9213.

16. Chandra RK. Immunocompetence in undernutrition. J Pediatr 1972; 81:1194-2000. 
17. Hafez M, Aref GH, Mehareb SW, Kassem AS, El-Tahhan H, Rizk Z, et al. Anti-body production and complement system in protein energy malnutrition. J Trop Med Hyg 1977; 80:36-39.

18. Haller L, Zubler RH, Lambert PH. Plasma levels of complement components and comple-ment haemolytic activity in proteinenergy malnutrition. Clin Exp Immunol 1978; 34:248-252.

19. Neumann CG, Lawlor GJ Jr, Stiehm ER, Swenseid ME, Newton C, Herbert J, et al. Immunologic responses in malnourished children. Am J Clin Nutr 1975; 28:89-104.

20. Olusi SO, McFarlane H, Ade-Serrano M, Osunkoya BO, Adesina $\mathrm{H}$. Complement components in children with protein-calorie malnutrition. Trop Geogr Med 1976; 28:323-328.

21. Sirisinha S, Edelman R, Suskind R, Charupatana C, Olsom RE. Complement and C3-proactivator levels in children with protein-calorie malnutrition and effect of dietary treatment. Lancet 1973; 301:1016-1020.

22. Smythe PM, Brereton-Stiles GG, Grace HJ, Mafoyane A, Schonland M, Coovadia HM, et al. Thymolymphatic deficiency and depression of cell-mediated immunity in protein-calorie mal-nutrition. Lancet 1971; 298:939-944.

23. Suskind R, Edelman R, Kulapongs P, Pariyanonda A, Sirisinha S. Complement activity in children with protein-calorie malnutrition. Am J Clin Nutr 1976; 29:1089-1092.

24. Fischel EE. Serum complement as an indicator of the presence and degree of inflammatory reaction in various diseases. J Clin Invest 1953; 32:568.
25. Lichtenfeld JL, Wiernik PH, Mardiney MR, Zarko RM. Abnormalities of complement and its components in patients with acute leukemia, Hodgkin's disease, and sarcoma. Cancer Res 1976; 36:3678-3680.

26. Kim Y, Michael AF. Hypocomplementemia in anorexia nervosa. J Pediatr 1975; 87:582-585

27. Palmblad J, Fohlin L, Norberg R. Plasma levels of complement factors 3 and 4, orosomucoid and opsonic functions in anorexia nervosa. Acta Paediatr Scand 1979; 68:617-618.

28. Wyatt RJ, Farrell M, Berry PL, Forristal J, Maloney MJ, West CD. Reduced alter-native complement pathway control protein levels in anorexia nervosa: response to parenteral alimentation. Am J Clin Nutr 1982; 35:973-980.

29. Flierl MA, Gaudiani JL, Sabel AL, Long CS, Stahel PF, Mehler PS. Complement C3 serum levels in anorexia nervosa: a potential biomarker for the severity of disea-se? Ann Gen Psychiatry 2011; 10:16.

30. Pomeroy C, Mitchell J, Eckert E, Raymond N, Crosby R, Dalmasso AP. Effect of body weight and caloric restriction on serum complement proteins, including Factor D/adipsin: studies in anorexia nervosa and obesity. Clin Exp Immunol 1997; 108:507-515.

31. Choy LN, Rosen BS, Spiegelman BM. Adipsin and an endogenous pathway of comple-ment from adipose cells. J Biol Chem 1992; 267:12736-12741.

32. Sigal LH, Snyder BK. Low serum complement levels in anorexia nervosa. Am J Dis Child 1989; 143:1391-1392. 